\title{
6 Disquotationalism and the Compositional Principles
}

\author{
Richard Kimberly Heck
}

[S]emantics ... is a sober and modest discipline which has no pretensions of being a universal patent-medicine for all the diseases of mankind, whether imaginary or real. You will not find in semantics any remedy for decayed teeth or illusions of grandeur or class conflicts. Nor is semantics a device for establishing that everyone except the speaker and his friends is speaking nonsense.

(Tarski, 1944, p. 345)

In their paper "The Use of Force Against Deflationism", Dorit Bar-On and Keith Simmons (2007, p. 61) helpfully distinguish three sorts of deflationary theses about truth. Metaphysical deflationism is a thesis about the property of truth, namely, that it is insubstantial, or that it has no essential nature, so that a theory of truth-a correspondence or coherence theory of truth, say-is both unnecessary and impossible. Linguistic deflationism is a thesis about the word "true", namely, that its meaning is adequately explained by Alfred Tarski's convention (T) or something along the same lines. Conceptual deflationism is a thesis about the role that the notion of truth may legitimately play in our theorizing, namely, that there are no interesting connections between truth and other concepts, such as meaning or belief. Rather, the notion of truth serves only an 'expressive' function, allowing us to formulate certain claims that we could not state without it, but playing no essential explanatory role (see e.g. Field, 1994, §5; Williams, 1999, p. 547).

Most deflationists seem to regard the linguistic thesis as fundamental. Exactly how the metaphysical thesis is supposed to follow from it has never been clear to me, probably because I do not understand what it is supposed to mean that truth is not a 'substantial property' (cf. Field, 1994 , p. 265, n. 19). But the real issue, in any event, concerns the conceptual thesis. Deflationists have generally regarded it as following from the linguistic thesis: Surely an expression that is explained in terms that make it all but redundant cannot play any essential explanatory role. In practice, the argument for this claim takes a form made familiar by Paul Horwich (1990). The work the notion of truth appears to do in various 


\section{Richard Kimberly Heck}

settings, it is claimed, can in fact be done entirely by a notion of truth that is stipulatively introduced in accordance with the tenets of linguistic deflationism. So the dialectic consists of the anti-deflationist's identifying some theoretical setting in which the notion of truth seems to be doing important explanatory work and the deflationist's attempting to show that the role the truth-predicate is playing in that context is, in fact, purely expressive. What it is for a use of the truth-predicate to be 'purely expressive' is a question to which we'll return.

Bar-On and Simmons's main purpose in their paper is to show that conceptual deflationism does not follow from linguistic and metaphysical deflationism. In particular, they argue that Gottlob Frege, though he was a linguistic deflationist, is not a conceptual deflationist (Bar-On and Simmons, 2007, §II) and that Robert Brandom, though he is both a linguistic and a metaphysical deflationist, is not a conceptual deflationist, either (Bar-On and Simmons, 2007, §III). More precisely, Bar-On and Simmons argue that the notion of truth plays an essential role both in Frege's account of assertion and in Brandom's account of 'commitment', and that in neither case is truth's role merely expressive. They do not, however, actually defend Frege's claim that assertion is the presentation of a thought as true, ${ }^{1}$ nor Brandom's account of commitment in terms of taking to be true, so it is open to a deflationist simply to reject those accounts. Deflationists hold that truth's only legitimate role is expressive. They need not deny that less enlightened philosophers have tried to make other uses of it.

Frege's own attitude toward truth is nonetheless instructive. On the one hand, Frege famously insists that "the sentence 'The thought that 5 is a prime number is true' contains ... the same thought as the simple '5 is a prime number'" (Frege, 1984c, op. 34). On the other hand, truth plays an absolutely central role in Frege's thought about language and, in particular, in the semantics that he develops for his formal language in Part I of Grundgesetze der Arithmetik (Frege, 2013). For Frege, the most fundamental linguistic unit, from a logical point of view, is the sentence; the most basic semantic fact about a sentence is its being true or false; and the sense of a sentence-the thought it expresses-is its truth-condition. How can Frege hold all these views? What explains the apparent tension is the fact that Frege's deflationary remarks always concern ascriptions of truth to what he called 'thoughts' (that is, to propositions, more or less). ${ }^{2}$ There is no reason to think that Frege was a linguistic deflationist about sentential truth. Frege never expresses a view about the meanings of sentences like "'Snow is white' is true", probably because, as Sir Peter Strawson (1950, pp. 129-131) makes clear, attributions of truth to sentences (let alone to utterances) are extremely uncommon in ordinary language. In so far as Frege was a deflationist at all, then, he was a deflationist about propositional truth, not about sentential truth. And, in the context of Frege's semantics, 
the notion of truth that is in play is one that applies not to thoughts but to sentences. So Frege is no kind of deflationist about the notion of truth that plays a role in his semantic theory, that is, in the theory of truth he develops for his formal language.

A semantic theory of the sort Frege was the first to develop is a theory of truth, however, only in Tarski's sense, not in the sense in which the coherence theory is a theory of truth. But one need not think it is possible, or even desirable, to have a theory of truth in that sense-the sense relevant to metaphysical deflationism-to think that the notion of truth might do interesting and useful work (see e.g. Davidson, 1990). ${ }^{3}$ Truthconditional semantic theories are about truth just as they are about sentences and other linguistic items, and if the role truth plays in such theories cannot be revealed as purely expressive, then conceptual deflationism is false. Now, questions about the role that truth plays in semantic theory are, as we have already said, questions about the truth and falsity of sentences ${ }^{4}$ so what we need to ask is whether linguistic deflationism about sentential truth provides us with the resources to unmask the use of truth in semantics as purely expressive. To put it differently, the question is whether deflationism about sentential truth is consistent with taking semantics seriously. ${ }^{5}$

I shall henceforth use the now common term 'disquotationalism' for deflationism about sentential truth. The term comes from W. V. O. Quine:

By calling ["snow is white"] true, we call snow white. The truth predicate is a device of disquotation.... We need it to restore the effect of objective reference when for the sake of some generalization we have resorted to semantic ascent.

(Quine, 1986, p. 12)

The linguistic part of the disquotationalist thesis is thus that the two sentences

(1) Snow is white.

(2) "Snow is white" is true.

are not just materially equivalent but equivalent in some much stronger sense that makes the truth-predicate "dispensible when attributed to sentences that are explicitly before us" (Quine, 1987, p. 214). ${ }^{6}$ Quine would never call such pairs of sentences 'synonymous', of course, and he denies that (1) and (2) are necessarily equivalent (Quine, 1956, p. 187). What he says instead is that "[a]scription of truth just cancels the quotation marks" (Quine, 1990, p. 80). Hartry Field (1994, p. 250) expresses a similar idea when he says that (1) and (2) are "fully cognitively equivalent", and, unlike Quine, Field (1994, p. 258) explicitly regards their equivalence as a "conceptual necessity". 


\section{Richard Kimberly Heck}

This is an extremely strong claim, and one that has some very odd consequences. As Field $(1994, \S 9)$ both notes and emphasizes, for example, the following is true if the truth-predicate is read disquotationally: ${ }^{8}$

(3) Even if "snow" had meant grass, the sentence "snow is white" would still have been true.

That is because it is equivalent to:

(4) Even if "snow" had meant grass, snow would still have been white.

And that is because, as Field (1994, p. 266) remarks, echoing Quine, "to call 'Snow is white' disquotationally true is simply to call snow white," whether or not we are inside a modal context. But surely (3) is false. ${ }^{9}$

This is not a dispensible feature of the truth-predicate as a disquotationalist understands it. It is, in fact, central to conceptual disquotationalism, that is, to how disquotationalists understand the 'expressive' function of the truth-predicate. Suppose, for example, that I were to say:

(5) The axioms of Euclidean geometry are not all true, but they might have been.

One might think that (5) is true for the boring reason that the sentences that express the axioms of Euclidean geometry might have meant something else. But, or so Field (1994, p. 265) argues, if "true" as it occurs in (5) is understood in accord with the tenets of disquotationalism, then (5) says that Euclidean geometry is contingently false. In particular, (5) is supposed to express exactly what:

(6) It is not the case that EG, but it might have been the case that EG.

expresses, where "EG" abbreviates the conjunction of the axioms of Euclidean geometry. As it happens, there are infinitely many such axioms, ${ }^{10}$ so we cannot actually write that conjunction down. But that, say disquotationalists, is precisely what makes the disquotational truthpredicate so useful: It allows us to express what (6) does without having to write out an infinite conjunction (see e.g. Quine, 1970, pp. 11-13).

Similarly, if I were to say:

(7) It is sometimes possible to see objects behind the sun because the axioms of Euclidean geometry are not all true.

then that is supposed to be a way for me to affirm that the non-Euclidean character of space is responsible for the somewhat surprising behavior of photons, not to make the absurd claim that optics is beholden to the 
semantics of English. But if that is to be so, then "The axioms of Euclidean geometry are all true" must simply express what the axioms of Euclidean geometry jointly do and, in particular, must not have any extra, 'semantic' content (Field, 1994, p. 266). If $\ulcorner$ “ $A$ " is true $\urcorner$ did have some content beyond that of $A$ itself, then that extra content might figure in causal explanations that invoked the notion of truth. It would not yet follow that truth did have some explanatory role to play (i.e., that conceptual disquotationalism was false), but the usual strategy for showing that truth doesn't play such a role would fail. ${ }^{11}$

Consider, for example, the standard response to the so-called success argument. We often explain people's ability to satisfy their desires in terms of the truth of their beliefs, so it looks as if truth is playing an explanatory role here. For example, we might explain how Alex managed to satisfy their desire for a beer in terms of the truth of their belief that there were beers in the cooler. Deflationists regard the mention of truth here as gratuitous: If what allowed Alex to satisfy their desire was the fact that their belief that there were beers in the cooler was true, then what allowed them to satisfy their desire was really just the fact there were beers in the cooler; the truth-involving explanation reduces to an object-level explanation. But if $A$ and $\ulcorner A$ " is true $\urcorner$ are not intersubstitutable inside the scope of "because", then this reduction fails. ${ }^{12}$ Of course, there might be other ways of resisting the success argument. But the most common strategy for doing so will have failed.

To summarize, disquotationalists have generally regarded $A$ and $\ulcorner$ " $A$ " is true $\urcorner$ (where "true" is read disquotationally) as equivalent in some sense strong enough to license intersubstitution in modal and causal contexts. That view flows from their commitment to conceptual disquotationalism, since, if $\ulcorner$ " $A$ " is true $\urcorner$ had some content beyond that of $A$ itself, ${ }^{13}$ that would open up the possibility that truth might have some important theoretical role to play. In that sense, disquotationalism is an heir to the redundancy theory: As we have already seen Quine put it, "true" would be dispensible were it not for our need to make certain kinds of generalizations.

Now, one might have wanted to say instead that the reason (5) expresses the contingency of what the axioms express is because the 'axioms' are not sentences but what those sentences express. That is, truth is being predicated not of sentences but of propositions (Heck, $2004, \S 2$ ). But this is not a line that a disquotationalist can take, since invoking propositions threatens to commit us to a substantial notion of representational content, which is part of what disquotationalism opposes (Field, 1994, pp. 266-267). A disquotationalist precisely does not want to understand attributions of truth to sentences in terms of the truth of the proposition the sentence expresses. Propositions (in anything but a pleonastic sense) are anathema to disquotationalism. The 
disquotationalist view, rather, is that attributions of truth to sentences are primitive, and they are to be understood in terms of disquotation. ${ }^{14}$

Still, it is often useful, when one is trying to understand what a disquotational truth-predicate is supposed to be, to compare it to a propositional truth-predicate. The claim that $A$ and $\ulcorner\mathrm{It}$ is true that $A\urcorner$ are equivalent in some very strong sense seems reasonable. ${ }^{15}$ For that reason, this sentence:

(8) Even if "snow" had meant grass, it would still have been true that snow was white.

is unproblematically true. But the disquotationalist's (3) is intended to be equivalent to (8), though it uses a sentential truth-predicate rather than a propositional one, so as to avoid the commitment to propositions. When "true" is read disquotationally, then, $\ulcorner$ " $A$ " is true $\urcorner$ is supposed to be just as obviously, and just as strongly, equivalent to $A$ as $\ulcorner$ It is true that $A\urcorner$ is. ${ }^{16}$

As noted above, the underlying point is that, if $\ulcorner$ " $A$ " is true $\urcorner$ had some content beyond that of $A$ itself, then that content could well be essential to putative explanations in which attributions of truth appeared. It would not follow that conceptual disquotationalism was false, but the typical strategy for establishing it would no longer be available. Uses of the truth-predicate could not simply be eliminated in the way disquotationalists propose, even when truth was ascribed to a single, explicitly specified sentence, let alone when it was used in generalizations, as it is in semantics.

A simple example of such a generalization is:

(9) $\ulcorner A$ and $B\urcorner$ is true iff $A$ is true and $B$ is true.

Following Field (2005), I shall call such generalizations 'compositional principles'. And the main question I want to discuss in the remainder of this chapter is how disquotationalists should understand the use of the truth-predicate in such principles, which are central to certain sorts of semantic theories. ${ }^{17}$ Even in (9), the use of the truth-predicate is supposed to be 'purely expressive'. The first question we shall consider below is: How so exactly?

I shall argue in $\S 6.1$ that the truth-predicate is not being used in (9) to express an infinite conjunction, as is often suggested. I shall then turn, in $\S 6.2$, to a prior question, namely, what right disquotationalists even have to compositional principles. As we shall see, Field (2005) has offered an answer, one that also yields an answer to the question what expressive role a disquotationalist should regard truth as playing in those principles. I shall show in $\S 6.3$, however, that Field's method for generating compositional principles over-generates and then argue, in $\$ 6.4$, that this 
reveals a deeper problem, which is that what Field's method yields simply are not compositional principles as they are understood in semantic theory. In particular, part of what (9) is typically understood to express is that conjunction is truth-functional, and Field's account would apply whether or not "and" was truth-functional.

Let me acknowledge something in advance. I shall be arguing that disquotationalism is committed to claims that may seem so absurd that no one could possibly accept them. This is worrying. But they are no more absurd than (3), in the end, and they flow from exactly the same source: The insistence that the primary function of "is true" is simply to erase quotation marks. That, obviously, is the very core of disquotationalism.

\subsection{What Expressive Role Does “True” Play in Compositional Principles?}

As mentioned above, disquotationalists regard the truth-predicate as merely an 'expressive' device. People sometimes put this point by saying that the truth-predicate allows us to make generalizations we could not make without it. But the slogan can't just mean that. Every predicate allows us to make generalizations we could not make without it. For example, the predicate "blue" allows us to express the generalization "All pigs are blue", which we could not express if we did not have the word "blue" in our language (or a synonym). So the disquotationalist slogan must mean something else. Which, of course, it does.

When disquotationalists characterize the truth-predicate as a 'device of generalization', what they mean is that it gives us a way to express generalizations all of whose instances we can already assert. It's just the generalization that we can't assert. That distinguishes the cases involving "true" from the case of "All pigs are blue". Not even the instances of "All pigs are blue" can be asserted without the use of "blue". More precisely still, the truth-predicate is supposed to act as a "device of infinite conjunction' (Field, 1994, §5; Halbach, 1999). In the cases of interest, we shall be able to assert the various instances of some generalization, but, because there are infinitely many such instances, we cannot actually assert them all, absent some mechanism for forming infinite conjunctions, which is exactly what the truth-predicate is supposed to give us-much as in the cases of (5) and (7) above.

Consider, for example, the law of excluded middle:

(10) Every sentence of the form $A \vee \neg A$ is true.

The disquotationalist's suggestion is that (10) means no more and no less than that either Bill smokes or Bill does not smoke, and either Fred runs 


\section{Richard Kimberly Heck}

or Fred does not run, and so forth. The individual instances-"Either Bill smokes or Bill does not smoke", "Either Fred runs or Fred does not run"- have nothing to do with truth. To express the generalization, of course, what we need to do is quantify over these instances. What we seem to want to say is thus something like:

(11) For all $S$, if $S$ is of the form $A \vee \neg A$, then $S$.

But that, familiarly, is ill-formed, since $S$ is occupying both term and sentence positions. What the truth-predicate does, according to disquotationalists, is to solve this syntactic problem by converting the position occupied by a sentence into one occupied by a term: "Fred runs or Fred does not run" is replaced by "'Fred runs or Fred does not run' is true", and our generalization can then expressed as:

(12) For all $S$, if $S$ is of the form $A \vee \neg A$, then $S$ is true.

All we're trying to do here, or so disquotationalists say, is to wrap the instances of $A \vee \neg A$ into a neat package and affirm them, all at once. The role the truth-predicate is playing is thus purely grammatical, and (12) means no more than what (11) was supposed to mean: It simply expresses the infinite conjunction that either Bill smokes or Bill does not smoke, and either Fred runs or Fred does not run, and so forth. In particular, (12) has no more to do with truth, semantics, or logic than would that infinite conjunction, if only we could write it down.

There are several difficulties with this idea. First of all, it is a delicate matter just how we should understand the claim that such sentences as (10) 'express' infinite conjunctions. As Anil Gupta (1993, §III) argues, "express" here has to be understood in a very strong sense-which makes it surprising that so little effort has been made to articulate what that sense is. ${ }^{18}$ The only serious attempt to do so, which is due to Volker Halbach (1999), cannot be regarded as successful (Heck, $2004, \S 3$ ). Worse, as Gupta also notes, this sort of proposal appears to conflate the truth of a generalization with the joint truth of its instances. The statement that all sentences of the form $A \vee \neg A$ are true has nothing to do with which instances of that form happen to be present in the language. On the contrary, excluded middle is supposed to be a law: It is supposed to be, in the usual sense, 'projectible'. Even if new sentences are added to our language, so that $A \vee \neg A$ comes to have new instances, those too are required to be true.

I shall not pursue these complaints further here, however, as sympathetic with them as I may be. There is a more important point in the vicinity: Compositional principles simply are not statements in which the truth-predicate is plausibly being used as a device of infinite conjunction. ${ }^{19}$ 
The problem is very simple. The only 'infinite conjunction' we might plausibly take (9) to express is far too weak to have any chance of being what it actually does express. Formalize (9) as:

$$
\forall x \forall y[\mathrm{~T}(\ulcorner x \wedge y\urcorner) \equiv \mathrm{T}(x) \wedge \mathrm{T}(y)]
$$

Which sentences not involving the truth-predicate are supposed to count as instances of the infinite conjunction allegedly expressed by $(13) ?{ }^{20}$ It is hard to see what they might be if not sentences of the form: $A \wedge B \equiv A \wedge$ $B$, so that (13) expresses the infinite conjunction of such claims as "Fred runs and Bill walks iff Fred runs and Bill walks", that is, the infinite conjunction of a bunch of instances of $p \equiv p$. That might sound like music to the disquotationalist's ears. But it should not.

Consider these two generalizations: ${ }^{21}$

(14) $\forall x \forall y[T(\ulcorner x \wedge y\urcorner) \equiv T(\ulcorner x \wedge y\urcorner)]$

(15) $\forall x \forall y[T(\ulcorner x \wedge y \equiv x \wedge y\urcorner)]$

If (13) is supposed to express an infinite conjunction, then presumably these do, as well. And there appears to be no option but to take them, too, to express the conjunction of all sentences of the form: $A \wedge B \equiv A \wedge B$. But these are all very different. For example, (14) is logically valid. And, while (15) is not itself logically valid, it follows from any set of principles entailing that all instances of a truth-functionally valid schema are true (for example, that very principle). ${ }^{22}$ But (13), together with similar principles, at least, has significant logical strength (Heck, 2015, 2018a).

The point, then, is that (13), (14), and (15) have very different logical properties. It follows, or so it seems to me, that they cannot all express the same infinite conjunction. On the contrary, at most one of them can express the infinite conjunction of sentences of the form: $A \wedge B \equiv A \wedge B$. But if any of these expresses that infinite conjunction, then surely it is (15), which does so in precisely the sense in which $\forall x[T(\ulcorner x \vee \neg x\urcorner)]$ expresses the conjunction of instances of the law of excluded middle. But then (13) does not express that infinite conjunction, and there is no other infinite conjunction that it plausibly does express.

The point applies to other compositional principles as well, such as:

$$
\forall x[T(\ulcorner\neg x\urcorner) \equiv \neg T(x)]
$$

If (16) expresses an infinite conjunction, it can only be the conjunction of all sentences of the form: $\neg A \equiv \neg A$. But, if so, then that infinite conjunction seems equally to be what is expressed by these two generalizations:

(18) $\forall x[T(\ulcorner\neg x \equiv \neg x\urcorner)]$ 


\section{Richard Kimberly Heck}

Once again, (16), (17), and (18) have very different logical properties, and at most one of them can express the infinite conjunction of all sentences of the form: $\neg A \equiv \neg A$. But (18) expresses that conjunction if anything does, so (16) does not express it.

I have heard it said in conversation that disquotationalists do not really mean that "true" is always used to express infinite conjunctions, but that this is its 'purpose' or 'role' in our language. But I have no idea what to make of such teleological claims. Most words do not have 'purposes', except to allow us to express whatever concepts they are used to express, and I see no reason to regard "true" as different from other words in this respect. ${ }^{23}$ Moreover, even if the truth-predicate had been explicitly introduced so as to allow us to express infinite conjunctions, it would not follow that, once we had it, we could not use it for quite different purposes, including ones that involved truth's playing a significant explanatory role. ${ }^{24}$ The disquotationalist therefore owes us an answer to the question what 'purely expressive' role the truthpredicate plays in compositional principles, if it is not to allow us to formulate infinite conjunctions.

\subsection{Disquotationalist Derivations of Compositional Principles}

Disquotationalists often seem to be of two minds about compositional principles. On the one hand, for example, Field (1994, p. 269) insists that "compositional principles have no interest in their own right". On the other hand, however, Field is of course aware that there are those who find such principles as:

(9) $\ulcorner A$ and $B\urcorner$ is true iff $A$ is true and $B$ is true.

to be of substantial interest. So he wants to be able to explain both why such principles are true, when they are, and why they are nonetheless insubstantial and can do no explanatory work.

There is a history here. In his book Truth, which helped launch contemporary deflationism, Horwich (1990) suggested that we can get everything we need to know about truth from the 'minimal' theory that consists just of the T-sentences. ${ }^{25}$ It is obvious, however, that a theory of truth containing just the T-sentences is very, very weak. ${ }^{26}$ Without such principles as (9), it's hard to see how such a truth-predicate could be of much use at all. It certainly could not be used for the sorts of purposes for which the truth-predicate is typically used in logic. ${ }^{27}$

One might well think, however, that the compositional principles can be derived from the T-sentences-or, better, from the 'T-scheme', thought of as an axiom scheme having the T-sentences themselves as instances. The argument proceeds as follows: ${ }^{28}$ 
(i) " $A$ and $B$ " is true iff $A$ and $B$.

(ii) " $A$ " is true iff $A$.

(iii) " $B$ " is true iff $B$.

(iv) " $A$ and $B$ " is true iff " $A$ " is true and " $B$ " is true.

The first three steps are delivered by the T-scheme; the last then follows by simple propositional reasoning.

Prima facie, this argument has two serious problems. First, it does not appear to be an argument at all. An argument consists of a sequence of claims allegedly related in some relevant way (e.g., deductively). But this 'argument' does not consist of a sequence of claims, and it is not at all obvious how to interpret it. This leads to the second problem: In so far as one does have some idea how to interpret this argument, one wants to regard " $A$ " and " $B$ " as variables. But then these variables appear both inside and outside quotation marks, something that is usually regarded as problematic.

One charitable way to interpret the 'argument' is to regard it not as an argument but as an argument schema. So understood, however, the argument fails to show what its proponents claim it shows. What the schematic argument shows is that we can prove every instance of (9). That, as Gupta (1993, p. 67) emphasizes, is not at all the same thing as being able to prove (9) itself. Indeed, if our background logic is first-order logic, or some other logic for which the compactness theorem holds, the generalization (9) cannot follow from its infinitely many instances. Otherwise, it would have to follow from finitely many of them, which it obviously does not (Shapiro, 1998, p. 496).

One might think the disquotationalist can simply concede this point. ${ }^{29}$ What the disquotationalist needs to show is that an 'insubstantial' theory of truth can do the work for which a 'substantial' theory of truth is supposed to be needed. The suggestion, then, in response to the foregoing, would be that what needs amending is just the proposed content of that 'insubstantial' theory: It should not contain just the T-sentences, or something of the sort, but also the sorts of generalizations we've been discussing. That is: The disquotationalist should just claim the compositional principles as their own.

This reply begs the question whether the disquotationalist actually has a right to the compositional principles. Worse, it is utterly ad hoc. The suggestion is that we should add generalizations like (9) to the 'minimal' theory containing just the T-sentences. But which generalizations are 'like' (9)? Discussion of these issues tends to idealize by taking the language to which the truth-predicate applies to be a formal (usually firstorder) language. And, in that case, we know well enough which compositional principles will be needed to allow us to make the generalizations the truth-predicate typically allows us to make. ${ }^{30}$ But disquotationalism isn't a view about truth as applied only to the sentences of formal 


\section{Richard Kimberly Heck}

languages. ${ }^{31}$ Truth, at least as it is used in semantics, applies to sentences of natural language. But then there is no clear limit to the sorts of compositional principles we will need to add. Indeed, if we take the case of firstorder languages as our model, then, in that case, what we need to add to the minimal theory, to make it do the work we need it to do, is a fullblown Tarski-style theory of truth, as Field (1999, pp. 534-535) himself has noted. That makes me suspect that, in the case of a natural language, what would be needed is what, from a different point of view, would be regarded as constituting a full semantic theory for the language in question. That makes the question what right a disquotationalist has to compositional principles pressing once again. ${ }^{32}$ Compositional principles are the very principles that semantic theories articulate, and truth appears to play a substantial role in such theories. If so, then "Disquotationalism doesn't work without the compositional principles, so we'd better add them" looks worryingly like another way of saying "Disquotationalism doesn't work, so we shouldn't be disquotationalists".

If something like the schematic argument rehearsed above could be resuscitated, however, then the problems we have been discussing would vanish. In light of our discussion in $\S 6.1$, however, the disquotationalist must abandon the claim that the compositional principles express infinite conjunctions; in light of Gupta's criticisms, they must also abandon the claim that compositional principles simply follow from their instances. But the possibility is still open, at least in principle, that the compositional principles should follow from certain general principles about truth that the disquotationalist anyway accepts. In particular, compositional principles might follow from the T-scheme, itself understood as having a certain kind of generality, rather than simply as a convenient way of summarizing the infinite list of its instances. And a form of this proposal has been developed by Field (2005).

The contrast to which I have just alluded, between two ways of understanding the T-scheme, is one that has been of significant interest to philosophers of logic and mathematics. Consider, for example, the induction scheme of Peano arithmetic:

$$
A(0) \wedge \forall x(A(x) \rightarrow A(S x)) \rightarrow \forall x A(x)
$$

There are two ways of understanding this scheme. One is to take it as simply a convenient shorthand for the infinite list of 'induction axioms' of PA. The other is to regard it as having a kind of generality, so that the scheme itself is, in some sense, the real axiom.

The contrast emerges when we consider what ought to happen when we expand the language of PA, say, by adding a function-symbol for exponentiation. ${ }^{33}$ If we understand the induction scheme in the first way, so that it is just a compact way of summarizing the real axioms, of which there are infinitely many, then it is of no significance that the 
expansion of the language introduces new sentences of the same form as the induction axioms we already accept. That the axioms we accept have a common form is of no interest beyond the fact that it permits such a compact summary of them. We might call such a conception of the induction scheme static.

On the other way of understanding the scheme, (19) is not just a compact way of listing a bunch of axioms. The common form of those axioms is precisely what is of interest. The fact that the expanded language contains new sentences of that form then does provide us with new axioms. The scheme is thus dynamic or, as it is more often put, 'open-ended'.

It is the static conception that is usually regarded as the 'official' one in mathematical logic, but Solomon Feferman (1996) has shown that the dynamic conception can be made to do mathematical work. ${ }^{34}$ The dynamic conception has also been put to philosophical work by Vann McGee (1997) and to joint philosophical and technical work by me (Heck, 2011, 2018b). It is probably fair to say that the dynamic conception remains controversial. But it is also fair to say, or so it seems to me, that it is actually the more natural of the two. And it is, I think, pretty clearly what the founders of modern logic (e.g., Zermelo) had in mind.

Moreover, it is the dynamic conception that articulates how a disquotationalist should, and most disquotationalists do, understand the role of the T-scheme. The T-scheme is not supposed to be a static summary of a bunch of principles that apply only to our language as we now have it, so that the introduction of a new expression would give us no reason to accept the new instances of the $\mathrm{T}$-scheme that then arise. On the contrary, disquotationalists understand the $\mathrm{T}$-scheme as a general principle-indeed, as the general principle-that governs the use of the truth-predicate (Field, 1994, p. 266, n. 20). To put the point in terms of conceptual role semantics, which many disquotationalists seem happy to adopt, ${ }^{35}$ the T-scheme summarizes a disposition that competent users of the truth-predicate must have, namely, to infer a sentence from an attribution of truth to that sentence, and conversely (or, more strongly, to substitute one for the other). So the T-scheme, as disquotationalists understand it, is 'open-ended', generating new instances of itself as the language evolves. ${ }^{36}$

Given this understanding of the T-scheme itself as a general principle, it is natural to wonder if there isn't some way of reasoning with it as a general principle so as to establish other general principles from it. Such reasoning is precisely what the schematic argument on behalf of (9) was attempting. As we saw, there are several problems one might have with that reasoning. But something like this reasoning is, in fact, quite common. I've come to realize, in fact, that I have sometimes given arguments of the same sort myself. ${ }^{37}$ 


\section{Richard Kimberly Heck}

The argument $\mathrm{I}$ have in mind is a well-known argument for the claim that the T-scheme fixes the extension of the truth-predicate. Here is the argument. Suppose that $\mathrm{T}(x)$ and $\tau(x)$ both satisfy the T-scheme. Then:

(i) $T(\ulcorner A\urcorner) \equiv A$, since $\mathrm{T}(x)$ satisfies the $\mathrm{T}$-scheme.

(ii) $\tau(\ulcorner A\urcorner) \equiv A$, since $\tau(x)$ satisfies the T-scheme.

(iii) $T(\ulcorner A\urcorner) \equiv \tau(\ulcorner A\urcorner)$, by propositional logic.

Since this holds for any sentence $A, \mathrm{~T}(x)$ and $\tau(x)$ have the same extension (on their common range).

It's a nice question how such arguments should be understood. One might suspect that the argument tacitly uses the notion of truth. I would not be unsympathetic. But, dialectically, I doubt this sort of worry will get much traction. The argument just rehearsed does not seem to employ the notion of truth, but to make perfectly good sense in its own right. And Field $(2005, \S 3)$ offers a detailed account of the sorts of principles that might govern such arguments, principles that suffice, he claims, to allow for proofs of all the compositional principles comprising a full truth-theory for any first-order language. In the case of the schematic argument for (9), the thought is that the various steps of the argument are, as Field puts it, "part of the language", in perfectly good order as they are. They just contain free schematic variables. And once we have reached the conclusion:

(iv) " $A$ and $B$ " is true iff " $A$ " is true and " $B$ " is true.

we may infer

(v) For all sentences $S$ and $T,\ulcorner S$ and $T\urcorner$ is true iff $S$ is true and $T$ is true.

by a principle allowing for the replacement of schematic letters that are everywhere within quotation marks by objectual variables ranging over sentences. The details are a little messy, but not that bad. ${ }^{38}$

For our purposes, the more important point is that Field's interpretation of such arguments also yields an answer to the question how disquotationalists should understand the expressive role played by the truthpredicate in compositional principles: It is 'syntactic sugar' that allows what is really substitutional quantification to appear as objectual quantification. ${ }^{39}$ Indeed, Field (1994, p. 259) suggests that the logic of schematic arguments "corresponds to a very weak fragment of a substitutional quantifier language".

The problem, then, is not that 'schematic reasoning' cannot be used to establish principles like (9). The problem, as we shall see in the next section, is that this kind of argument works too well. 


\subsection{Schematic Reasoning Over-Generates}

There is another argument that Field might have given for (9):

(i) " $A$ and $B$ " is true iff $A$ and $B$.

(ii) " $A$ and $B$ " is true iff " $A$ " is true and " $B$ " is true.

(iii) For all sentences $S$ and $T,\ulcorner S$ and $T\urcorner$ is true iff $S$ is true and $T$ is true.

The first two steps are justified by the disquotational character of the truth-predicate; the last, by principles governing schematic reasoning.

Once one notices this sort of argument, however, it becomes apparent that it can equally well be used to prove all sorts of other things, e.g.:

(20) For all sentences $S$ and $T,\ulcorner S$ because $T\urcorner$ is true iff $S$ is true because $T$ is true.

Thus:

(i) " $A$ because $B$ " is true iff $A$ because $B$.

(ii) " $A$ because $B$ " is true iff " $A$ " is true because " $B$ " is true.

(iii) For all sentences $S$ and $T,\ulcorner S$ because $T\urcorner$ is true iff $S$ is true because $T$ is true.

Here again, the first two steps are justified by the disquotational character of the truth-predicate; the last, by principles governing schematic reasoning.

One might think it obvious that this last argument should fail. Consider the adaptation of the original schematic argument to the case of "because":

(i) " $A$ because $B$ " is true iff $A$ because $B$.

(ii) " $A$ " is true iff $A$.

(iii) " $B$ " is true iff $B$.

(iv) " $A$ because $B$ " is true iff " $A$ " is true because " $B$ " is true.

That certainly does fail, since substitution of material equivalents is not permitted inside intensional contexts. Of course, for the disquotationalist, the first three biconditionals all hold "of conceptual necessity ... in virtue of the cognitive equivalence of the left and right hand sides" (Field, 1994, p. 258). But conceptual necessity, by itself, would not necessarily justify the inference to (iv). It is not even clear whether cognitive equivalence would justify it. ${ }^{40}$ But, as we saw earlier, the whole point of a disquotational truth-predicate is to allow us to make certain sorts of generalizations we could not make without it. This includes such cases as 
(7) It is sometimes possible to see objects behind the sun because the axioms of Euclidean geometry are not all true.

and related sentences that occur in the success argument. But (7) will not mean what the disquotationalist wants it to mean unless $A$ and $\ulcorner$ " $A$ " is true $^{\urcorner}$are intersubstitutable within the scope of "because". This intersubstutability principle is what is driving the argument for (20), so it ought to be acceptable to a disquotationalist.

This will no doubt seem odd, but it is a familiar oddity. One might equally well have thought that substitution of $\ulcorner$ " $A$ " is true $\urcorner$ for and by $A$ itself should not be permitted in modal contexts. But, as we saw earlier, Field (1994, p. 265) is explicit that it must be, and for good reason. So we can also prove a compositional principle for necessity:

(21) For all sentences $S$, $\ulcorner$ Necessarily, $S\urcorner$ is true iff, necessarily, $S$ is true.

Thus:

(i) "Necessarily, $A$ " is true iff, necessarily, $A$.

(ii) "Necessarily, $A$ " is true iff, necessarily, " $A$ " is true.

(iii) For all sentences $S$, $\ulcorner$ Necessarily, $S\urcorner$ is true iff, necessarily, $S$ is true.

Again, that the first step of this argument is legitimate, if "true" is read disquotationally, simply follows from what Field himself argues is required if "true" is to play the generalizing role he thinks it plays: $\ulcorner$ " $A$ " is true $\urcorner$ must be substitutable for and by $A$, even when it occurs in a modal context, lest

(5) The axioms of Euclidean geometry are not all true, but they might have been.

not mean what it is supposed to mean.

The same point emerges if one reflects on the fact, mentioned at the end of the last section, that, for a disquotationalist, the truth-predicate functions essentially as syntactic sugar sprinkled over an underlying substitutional quantifier. On that interpretation, (9) amounts to

$$
\Pi S \Pi T \Pi U\left[^{\prime} U \text { ' }=\text { 'S and } T \text { ' } \rightarrow U \equiv(S \text { and } T)\right]
$$

and (20) amounts to:

$$
\Pi S \Pi T \Pi U\left[{ }^{\prime} U \text { ' }=\text { ' } S \text { because } T \text { ' } \rightarrow U \equiv(S \text { because } T)\right]
$$

There is nothing whatsoever wrong with either of these-other than that they are trivialites, facts not of semantics but of orthography. ${ }^{41}$ 
Field (2005, pp. 23-24) discusses a closely related point in connection with the question whether his schematic treatment extends to belief attributions. The particular question at issue there is whether schematic reasoning can be used to prove:

(22) For all sentences $S$ and names $N,\ulcorner N$ believes that $S\urcorner$ is true iff $N$ believes that $S$ is true.

Field offers various reasons to doubt that (22) can in fact be proven schematically and expresses some doubt about (22) itself. But, for the reasons already given, I find Field's discussion hard to align with his disquotationalist commitments. ${ }^{42}$ From a semantic point of view, (22) is extremely dubious. But from the disquotational point of view, surely (22) ought to be correct. It has to be correct if the truth-predicate is to play the expressive role disquotationalists think it plays. Suppose I want to affirm John's belief in the Euclidean character of space. Then I might say, "John believes that the axioms of Euclidean geometry are all true". If that is not to be a comment on John's beliefs about the semantics of English, then $\ulcorner$ " $A$ " is true $\urcorner$ has to be equivalent to $A,{ }^{43}$ even inside hyperintensional contexts (cf. Field, 1994, pp. 265-266). So (22) seems to be provable in the usual way:

(i) " $S$ believes that $A$ " is true iff $S$ believes that $A$.

(ii) " $S$ believes that $A$ " is true iff $S$ believes that " $A$ " is true.

(iii) For all sentences $S$ and names $N,\ulcorner N$ believes that $S\urcorner$ is true iff $N$ believes that $S$ is true.

Obviously, this strategy is going to generalize.

Field $(2005$, p. 24) also expresses concern about the last step of the argument, since it "seems to depend for its plausibility on the assumption that we can unproblematically quantify into" the appropriate sort of context. But there is nothing wrong with quantifying into intensional or even hyperintensional contexts. We do so all the time in ordinary language. ${ }^{44}$ If 'quantifying-in' seems puzzling, it is because of other theoretical commitments we have. Specifically, the problems connected with quantifying-in arise because of our commitments regarding the semantics of quantification: We want to regard the quantified variable as ranging in such cases over ordinary objects (people and planets) rather than intensions or modes of presentation. Even more fundamentally, the reason that quantifying-in is a problem is simply that we think of variables as having values. If one thought of the truth of a quantified statement in terms of the truth of its instances, then, as Ruth Barcan Marcus (1972) was fond of pointing out, there would be no problem. Field cannot have it both ways. He cannot both suggest that we regard questions about the semantics of attitude attributions as "misguided" and 


\section{Richard Kimberly Heck}

then invoke the very problems that motivate such questions when trying to avoid unwelcome consequences of his own view.

But whatever the status of (22), it should be clear that few of Field's worries about it carry over to (20) and (21). There is no obstacle whatsoever to quantifying into causal or modal statements. And the suggestion-which we did not discuss-that (22) might fail because $N$ "may have peculiar beliefs about truth" (Field, 2005, pp. 23-24) has no analogue in those cases. While my own view, then, is that disquotationalists are committed to (22) as well as to (20) and (21), it is enough for what follows if they are committed only to the latter two. Indeed, it is enough if they are committed just to (21), though I shall focus in what follows on (20).

\subsection{Truth-Functionality}

\subsubsection{Compositional Principles and Truth-Functionality}

Friends of semantics will have greeted

(20) For all sentences $S$ and $T,\ulcorner S$ because $T\urcorner$ is true iff $S$ is true because $T$ is true.

with bemusement. But what exactly is supposed to be wrong with it? Why does it feel so different from

(9) $\ulcorner A$ and $B\urcorner$ is true iff $A$ is true and $B$ is true.

and related principles? As (9) is generally understood by friends of semantics, what it says, in part, is that the truth-value of a conjunction is entirely determined by the truth-values of its parts, i.e., that conjunction is truth-functional. It is the truth-value of the conjuncts that matters, but what the conjuncts contribute is just their truth-value and nothing else. Similarly, then, (20), as understood by friends of semantics, would tell us that the truth-value of " $A$ because $B$ " is wholly determined by the truth-values of $A$ and $B$ and the causal relationship between those truth-values (e.g., by whether the True because the False). That is barely coherent, but never mind. What the provability of (20) really shows us is that the proof of (9) goes through whether or not "and" is truthfunctional. So, if (9) is understood in the sense in which it is schematically provable, it does not affirm the truth-functionality of conjunction; so understood, then, it is not the compositional principle for "and" as friends of semantics would understand it; that principle is not schematically provable.

That went by pretty quickly. Let me fill in some details. 
Strawson (1952, pp. 79-82) famously denied that "and" is truthfunctional, on the ground that there is a temporal aspect to its meaning. ${ }^{45} \mathrm{~A}$ sentence like

(23) They got married, and they had a baby.

could be true, Strawson claimed, even though

(24) They had a baby, and they got married.

was false. But how this issue is decided has no effect whatsoever on whether (9) is true when the truth-predicate is read disquotationally. If truth is disquotational, then $\ulcorner$ " $A$ " is true and " $B$ " is true $\urcorner$ just means what $\ulcorner A$ and $B\urcorner$ means which is just what $\ulcorner$ " $A$ and $B$ " is true $\urcorner$ means, and that is the end of it, no matter what "and" actually means. If that were not so, then the truth-predicate could not be used, in the context of a conjunction, for the expressive purposes for which the disquotationalist thinks we need it. It follows that the sorts of arguments we have been examining do not allow the disquotationalist to prove the compositional principles in the sense that friends of semantics understand them. In particular, this sort of reasoning cannot be used to demonstrate the truthfunctionality of conjunction, which I take to be one of the central semantic facts about it-if, indeed, it is a fact about it.

I am assuming, of course, that whether "and" is truth-functional is an important semantic issue, one that will affect the form of the compositional principle we accept for it. Foes of semantics might not agree, but my goal here is not to convince them of the virtues of semantics. My goal is to argue that the notion of truth, as it appears in semantics, is not playing the merely expressive role that a disquotational truthpredicate plays: One cannot understand the use of the truth-predicate, in semantics, as purely disquotational, as just a tool of 'semantic ascent'. Rather, the notion of truth is doing serious theoretical work, and that work is nowhere more visible than in disputes over truth-functionality. The fact that "and" is truth-functional (if, again, it is a fact) is supposed to explain certain aspects of the behavior of that word, and the fact that "because" is not truth-functional is supposed to explain some of the ways in which it is unlike "and". So truth has a robust, explanatory role to play in semantics.

A disquotationalist might respond that truth-functionality is, to be sure, an important phenomenon, ${ }^{46}$ but that it is not a semantic but a logical phenomenon, one that has to do with what sorts of inferences are valid, not with whether (9) is true. Presumably, the inferences in question would be something like:

(i) $A$ and $B$. 


\section{Richard Kimberly Heck}

(ii) $B$ if, and only if, $C$.

(iii) Hence, $A$ and $C$.

Call these 'inferences constitutive of truth-functionality'.

Even at first sight, one ought to be suspicious of this sort of inferential characterization of truth-functionality. If the biconditional is not itself truth-functional, then it may license such substitutions in cases where the connective under discussion is not truth-functional. ${ }^{47}$ For example, if the biconditional expresses necessary equivalence, then it will license substitutions inside modal contexts. It is rarely held nowadays that the natural language conditional is truth-functional, so this sort of inference, formulated in natural language, almost certainly does not capture truthfunctionality. But, even if we set that worry aside, the offered condition is easily seen to be both too weak and too strong.

To see that the condition is too weak, consider the conditional itself. Then the inference in question takes the form:

(i) If $A$, then $B$.

(ii) $B$ if, and only if, $C$.

(iii) Hence, if $A$, then $C$.

This will be valid so long as the conditional is transitive, whether or not it is truth-functional, and the same goes for the case in which we substitute in the antecedent. The inferential conception would thus count any transitive conditional as truth-functional.

One might suggest, in response, that the inference should not be stated in terms of "if and only if", but in some other terms. One idea, for example, would be to take the second premise to be:

(ii') Either $B$ and $C$, or it is not the case that $B$ and it is not the case that C.

which is disquotationally equivalent to:

(ii") Either " $B$ " is true and " $C$ " is true, or " $B$ " is false and " $C$ " is false.

But this proposal has similar flaws. As mentioned earlier, it is controversial whether "and" is truth-functional. If it is not, then (ii') is not truth-functional, either, and the possibility will again arise that it will support inferences it should not. ${ }^{48}$

But however the inference is formulated, requiring it to be valid if a connective is to be truth-functional is too strong a condition. I have mentioned several times now that it is controversial whether "and" is truthfunctional. That question is not, however, decided simply by considering the truth-values of such sentences as (23) and (24). Even if those two 
sentences can have different truth-values, it does not follow that "and" is not truth-functional. The reason for the difference in truth-value might lie not in the meaning of "and" but in the interaction of the tenses on the verbs with each other and with other elements of the syntactic structure of the sentence. Such an account was developed by Barbara Partee (1984, §IV) in the context of Discourse Representation Theory, but similar accounts can be developed in other frameworks (see e.g. King and Stanley, 2004, §V).

Ultimately, of course, it is an empirical question what accounts for the temporal reading of conjunctions; that is, it is an empirical question whether "and" is truth-functional. But the point here is conceptual: One cannot read off from the truth-values of sentences in which "and" occurs whether it is truth-functional. There is too much else going on in such sentences for such an inference to be legitimate. If so, however, no inferential test of the sort we are considering can work. To steal from Hilary Putnam: Truth-functionality just ain't a matter of inference. ${ }^{49}$

One might respond that, if Partee is right, then (23) and (24) aren't, on the readings in question, actually conjunctions. They have some more complex structure. So, if we consider sentences that really are conjunctions, then the inferential test will work. But then the question is how we are supposed to tell which sentences 'really are' conjunctions. The point is not just that it is hard to know. The point is that, in practice, claims about what the structure of a sentence 'really is' are evaluated by considering how that sentence's having a given structure would affect its meaning. One can't even discuss this sort of question unless one has some sort of idea how structure-facts affect meaning-facts. ${ }^{50}$ But how structure affects meaning is what semantics is about-one of the things it is about, anyway. So the question whether (23) and (24) are 'really conjunctions' is one that makes no clear sense outside the semantic project.

This sort of point is perhaps easiest to understand in connection with quantification. Consider, for example:

(25) Most professors know some student who hates every class.

There are several possible readings for this sentence, but it seems to me that (25) cannot mean that every class is hated by some student that most professors know. ${ }^{51}$ Why not? The familiar answer is that, while the three quantifiers in (25) can take different scopes, not every possible ordering of the scopes is available. And surely something along those lines must be right. $^{52}$ But it is only a partial explanation, and it would be no explanation at all if we did not understand how scope affects meaning: (25) has the readings it does, and not others, because certain scope relationships are possible, and a sentence in which the quantifiers take these 


\section{Richard Kimberly Heck}

scopes has this meaning; one in which they take those scopes has that meaning; and to get this other (unavailable) meaning, the quantifiers would have to take these other scopes which, for some reason, they can't.

\subsubsection{Schematic Reasoning and Compositional Principles}

Toward the end of his paper on schematic reasoning, Field makes two suggestions:

First, it may simply be misguided to look for compositional truth or meaning principles for attitude constructions. Second ..., the fact that compositional principles of truth or meaning are straightforward for some constructions but not others is not fundamentally a fact about the application of the notion of truth or meaning to different constructions, but is simply a fact about the underlying logic of those constructions. Facts about the logic of these constructions explain the facts about how the notions of truth and meaning that apply to them, rather than the other way around.

(Field, 2005, p. 24)

The logic of "and" and "or" permits a simple derivation of the compositional principles for them, but the logic of attitude constructions, Field thinks, does not. Now, as I have said, if the truth-predicate is disquotational, then that is wrong. But set that aside. Suppose we accept, as almost anyone would, ${ }^{53}$ that $A$ and $\ulcorner$ " $A$ " is true $\urcorner$ are materially equivalent. Then it looks as if schematic reasoning will permit the derivation of the compositional principle for "and", if it is true (i.e., if "and" is truth-functional), though it will not then permit the derviation of the compositional principles for "because" and "necessarily". That is, it looks as if (9) will be provable by schematic reasoning (if it is true), just given the very weak assumption just mentioned. How then can (9) be regarded, as friends of semantics want to regard it, as an empirical hypothesis?

I do not mean to attribute this line of thought to Field, but it is naturally suggested by his paper, and it took me a while to formulate an answer to it. So it seems worth considering, at least briefly.

To see the response, consider:

(26) "Alex swims and Tony runs" is true iff Alex swims and Tony runs.

Friends of semantics would regard (26) as one of the empirical claims in whose explanation (9) figures. But (26) is just an instance of the Tscheme. How can it need explaining at all? There seems to be a way of knowing that (26) is true that simply involves reflecting on the meaning of the word "true". But even if (26) can, in this way, be known by 
reflection, or even a priori, it does not follow that (26) is not empirical, nor that it does not stand in need of explanation. I can know by reflection that I am here now, but it is an empirical fact nonetheless, and one that can be explained.

Moreover, my own view is that the full story about how one might come to know (26) on the basis of reflection is significantly more complicated than: 'true' disquotes (Heck, 2004, §5). The complications matter. In particular, one cannot come to know (26) by this sort of reflection unless one already understands the embedded sentence "Alex swims and Tony runs". That understanding, on my view (see Heck, 2007), partially consists in knowledge of (26). That need not make the reflective knowledge circular. It just means that, once one has come to know (26) in one way-by learning to speak the fragment of English of which the sentence it mentions is a part-and one has also come to understand the word "true", then another, more 'reflective' way to know (26) also becomes available (Heck, 2004, §3).

Something similar is true of compositional principles. The semantical view is that principles like (9) are more fundamental than such T-sentences as (26): Part of the reason (26) is true is because a conjunction is true just in case both its conjuncts are, but it is no part of why (9) is true that (26) is true. ${ }^{54}$ It is no threat to this position if, once such T-sentences are in place, one can do 'reverse semantics' and derive the more fundamental compositional principle for conjunction from the less fundamental $\mathrm{T}$-sentences it partly explains by reflecting on the pattern exhibited by such $\mathrm{T}$-sentences generally. ${ }^{55}$

It is no doubt an interesting question why such schematic derivations seem to be available in some cases but not in others. But there is an obvious sense in which Field's schematic arguments simply piggyback on genuine semantics: Field introduces deflated versions of whatever machinery is required by genuine semantics and then treats it schematically. ${ }^{56} \mathrm{I}$ suspect that such mimicry is also possible in other sorts of cases. The difference is simply that, in those other cases, more sophisticated sorts of semantic machinery will be involved. In many cases, there is, as yet, no semantic theory to mimic. If there were, then I'm sure Field could mimic it, too.

\subsubsection{A Brief History of Truth-Functionality}

I argued in $\$ 6.4 .1$ that truth-functionality cannot be characterized in terms of the validity of inferences. It is, rather, a semantic phenomenon, one that can only be characterized in terms of the notion of truth, which thus plays a role in semantics that is not simply expressive. The history of the notion of truth-functionality teaches us the same lesson. ${ }^{57}$

I used to think that the notion of truth-functionality was due to George Boole, but I was wrong. Boole does think of (what we would 


\section{Richard Kimberly Heck}

call) sentence-letters as having 'values', and he thinks of conjunction and the like as corresponding to operations on those values, with the values and the operations together forming (what we now call) a Boolean algebra. So Boole does think of conjunction as a function. But he does not think of it as a truth-function, because he does not think of the values of sentence-letters as truth-values. They are, rather, classes, subsets of the 'universe of discourse', which he originally regards, in The Mathematical Analysis of Logic, as comprised of 'cases' or 'circumstances': The value of a sentence-letter is the set of circumstances in which it is true (Boole, 1847, pp. 48ff).

By The Laws of Thought, Boole (1854, ch. XI, §16) had become dissatisfied with this view, because it requires "a definition of what is meant by a "case", which he thinks will involve us in matters beyond the bounds of logic. In this later book, then, he regards the universe of discourse as consisting of times-apparently, these are within the bounds of logic - and the value of a sentence-letter becomes the set of the times at which it is true. Other Booleans made yet other choices. But almost all the Booleans take the values of sentence-letters to be subsets of some universe of discourse. ${ }^{58}$ The crucial advantage of this view, as the early Booleans saw it, is that hypothetical judgements can thereby be unmasked as universal affirmative propositions, relations between classes. Thus, we find Boole writing:

Let us take, as an instance for examination, the conditional proposition "If the proposition $X$ is true, the proposition $Y$ is true". An undoubted meaning of this proposition is, that the time in which the proposition $X$ is true, is time in which the proposition $Y$ is true.

(Boole, 1854, ch. XI, §5, emphasis original)

More generally, the 'calculus of judgements' (sentential logic) can, in this way, be reduced to the 'calculus of classes' (Aristotelian logic, more or less), thus unifying what might otherwise have looked like unrelated parts of logic.

The question what comprises the universe of discourse has proved not to be the crucial point. Boole's great insight was precisely that, no matter what we take the universe to comprise, if we treat the sentential connectives as expressing set-theoretic operations on its power set, then the (Boolean) algebra so determined will validate the laws of classical logic. And the flexibility inherent in Boole's approach has proven a great advantage. His original view, that the universe comprises 'cases', inspired some of the earliest work on modal logic. His later view, that it comprises times, had a similar influence on tense logic.

Boole does regard the case in which the universe contains just one element as special. Then we have a two-element Boolean algebra, with elements Boole would have denoted " 1 " and " 0 ". But, even in this 
case, Boole does not interpret 1 and 0 as truth and falsity: They are the universe and the empty set, as they always are in his work. Boole regards this case as especially important because it makes the calculations in which he is interested especially easy. ${ }^{59}$ But-and this is the pointnone of this affects Boole's theory of those calculations, that is, his attempt to axiomatize the structure of a Boolean algebra, i.e., his attempt to formalize sentential logic. What I earlier called 'inferences constitutive of truth-functionality' were well-known to Boole. Identity, which functions like the biconditional, features prominently in Boole's calcuations, as do the substitutions that it licenses. But the notion of truth-functionality simply is not present, because Boole does not, as we have seen, think in terms of truth-values.

The notion of truth-functionality is not present in Frege's Begriffsschrift, either, though Frege does there present a complete formalization of sentential logic, and 'inferences constitutive of truth-functionality' are frequently made. Indeed, one of the rules governing the sign for 'identity of content', which acts much like the biconditional (and is written: $\equiv$ ), is proposition (52), which is a form of Leibniz's Law and which permits precisely the substitutions embodied in the 'inferences constitutive of truthfunctionality'.

The striking fact, though, is that, in Begriffsschrift, Frege simply does not explain the conditional in terms of truth and falsity. His explanation reads, rather, as follows:

If $A$ and $B$ stand for contents that can become judgements ..., there are the following four possibilities:

(i) $A$ is affirmed and $B$ is affirmed;

(ii) $A$ is affirmed and $B$ is denied;

(iii) $A$ is denied and $B$ is affirmed;

(iv) $A$ is denied and $B$ is denied.

Now

$$
ケ_{B}^{A}
$$

stands for the judgement that the third of these possibilities does not take place, but one of the other three does.

(Frege, 1967, §5, emphasis removed)

Frege does not think of the conditional as expressing any kind of function in Begriffsschrift (Linnebo, 2003), let alone a truth-function. He seems to get the idea that it expresses a function a few years later, from Boole. The idea that it expresses a truth-function, however, is Frege's own, and it does not appear until 1891, in his lecture Function and Concept (Frege, 
1984b, opp. 20ff). The crucial innovation Frege has made at that point is to introduce the notion of a truth-value-and with it the idea that sentences denote their truth-values. Then the way is open to regarding the conditional as, quite literally, expressing a truth-function: a function whose arguments and values are truth-values.

The notion of truth-functionality did not emerge, then, either from the algebraic manipulations we find in Boole nor from the codification of inference presented in Begriffsschrift. Though these earlier efforts no doubt help prepare the way, truth-functionality appears only within, and as a central part of, the semantic perspective that Frege embraces in his later writings.

I would suggest, in fact, not only that truth-functionality cannot be explained in terms of inference, but that even compositional principles like (9) do not really capture it. Properly to capture it, we need to follow Frege and think of sentences as having truth-values as their 'semantic values' and of connectives like "and" as operating on those values. ${ }^{60}$ That, in fact, is often how things are done in developed presentations of truth-theoretic semantics for natural languages (e.g., Larson and Segal, 1995). The possible semantic values for sentences, truth and falsity, form a two element Boolean algebra, and the semantic values of conjunction, disjunction, and the like are the operations of that algebra. In such a treatment, it is not just the particular clause for conjunction that expresses its truth-functionality, but the semantic framework in which that clause is stated. Semantic notions then play an even more fundamental role than they do if the theory is formulated simply using compositional principles. ${ }^{61}$

\subsection{Closing}

Donald Davidson (1984) famously takes the task of semantic theory to be the construction of a compositional theory of truth that delivers such theorems as:

(27) "Snow is white" is true iff snow is white.

Ironically, though, given how frequently (27) is used to illustrate the goals of semantic theory, we do not actually know how to formulate a theory that will generate it without getting a great deal else wrong. That is, we do not have a (widely accepted) semantics for mass terms. Field (1994, p. 269) thinks there may well be none to be had and so that it is a virtue of disquotationalism that it relieves us of the need to look for one. And Field (2005, p. 24) would further deny that any explanation of the truth of (27), of the sort that semantic theory purports to provide, is required, going so far as to suggest that "it may simply be misguided to 
look for compositional truth or meaning principles" in such cases. After all, if disquotationalism is true, then (27) is just a verbose way of writing:

(28) Snow is white iff snow is white.

and surely no deep explanation is needed of the truth of (28). So, ultimately, it seems unsurprising that disquotationalism cannot make good sense of such compositional principles as (9), or of semantic theory more generally.

It is of course open to a disquotationalist simply to insist that the use that semantic theory makes of the concept of truth, since it is not 'merely expressive', is illegitimate. And it is not my purpose here to convince anyone of the interest of natural language semantics, nor of linguistic theory more generally. My goal has simply been to force a choice between conceptual disquotationalism and semantics by showing that the work that the notion of truth does in semantic theory cannot be regarded as 'merely expressive', even in the simplest cases. As it happens, my own view is that the insights gained over the last few decades more than suffice to demonstrate the fruitfulness of the semantic enterprise and of the central role that the thesis of compositionality has played in shaping it. To be sure, there is no a priori guarantee that there are compositional principles to be found for mass terms, attitude constructions, and the like. But that is simply a reflection of the fact that the compositionality of natural language is an empirical hypothesis, and a strong one (which is part of why it has proven so fruitful). ${ }^{62}$ Quite generally, though, the difficulty of formulating a semantic theory for mass terms, or attitude constructions, or generics, or what have you, should be no more surprising than is the difficulty of formulating conditions on the use of resultatives, in syntax.

I choose, then, to embrace natural language semantics and to reject conceptual disquotationalism. But I have not argued for that choice here.

\section{Acknowledgments}

Thanks to the editors, Carlo Nicolai and Johannes Stern, for their comments on the chapter, which helped me to clarify one of its central arguments. Thanks also to John P. Burgess for conversations early in the history of the chapter that helped me to clarify some of its central ideas and to J. C. Beall for some very helpful remarks over lunch. A talk based upon this chapter was presented at a workshop on semantics held at Rutgers University in September 2012. Thanks to my commentator, Karen Lewis, whose remarks significantly improved the chapter, and to everyone present for their input, especially David Beaver, Josh Dever, Cian Dorr, Michael Glanzberg, Ernie Lepore, Zoltan Gendler Szabó, and Rich Thomason. Thanks to Ernie again for the invitation. 


\section{Notes}

1. For a nice historical discussion of this aspect of Frege's position, see Textor (2010). My own view is that there is something profoundly right about that position but that, to understand it properly, we need to see it as expressed through Frege's thesis that the reference of a sentence is its truth-value and, therefore, that the sense of a sentence-the thought it expresses-is its truth-condition (Heck and May, 2018, 2020). Which brings us to the next paragraph.

2. It's also important to appreciate the true purpose of Frege's deflationary remarks: to undermine the view that the relationship between a thought and its truth-value is that of subject to predicate rather than, as Frege thinks, that of sense to reference. For discussion, see Heck (2010), Heck (2012, Part I), and Heck and May (2018, esp. §5).

3. The opponent of deflationism also does not need an alternative to linguistic deflationism. If there is no simple explanation of what the word "true" means, then that simply shows that it is like most other words. That said, from a Davidsonian perspective, the correct axiom for sentential "true" would seem to be something along the lines of (see Heck, 2004, §4):

" $x$ is true" is true of $S$ iff $S$ is true.

The case of propositional "true" is more complicated only because of the presence of intensional language. But that is a separate problem.

4. Or, in a more developed setting, sentences and contexts, or utterances, or something of the sort. This complication will not be relevant here, so I will continue to speak of sentences. Indeed, disquotationalism famously has serious problems with context-dependence (Heck, 2004, §4), so ignoring it can only help my opponent.

5. It seems clear that deflationism about propositional truth is consistent with taking semantics seriously. Soames $(1988,1999)$ holds precisely such a combination of views. Semantics, as he sees it, assigns propositions to sentences (relative to contexts). Truth simply does not enter the picture. It's a more interesting question whether propositional deflationism is compatible with truth-conditional semantics.

6. Gupta (1993, esp. §IIII) spends a good deal of time emphasizing just how strong this equivalence needs to be. Much of what follows simply reinforces that point.

7. Strictly speaking, as Field (1994, pp. 250-251) notes, the latter sentence seems committed to the existence of the sentence "Snow is white", whereas the former sentence does not. So, officially, Field's view is that they are fully cognitively equivalent modulo that commitment. But Field himself tends to disregard this aspect of the view, and I will tend to do so as well. That said, Marian David (2005, §IV) argues that it is a more serious problem than is usually acknowledged.

8. If one is worried about the use of "means" in the antecedent, replace it by: Even if "snow" had been used the way "grass" is used, and conversely.

9. Some philosophers think sentences have their meanings essentially (see e.g. Simchen, 2012). I find the conception of 'sentence' on which such views are based to be incompatible with any plausible theory of human language comprehension. But we can set that issue aside here and simply reformulate (3) in terms of a particular uttertance made by me at some fixed time of a sentence specified purely syntactially: The claim is then that that utterance would have been false had "snow" meant grass. 
10. Assuming we are working in a first-order language. But, in the second-order case, the logic itself is not finitely axiomatizable.

11. Here again, this point is essentially due to Gupta (1993).

12. Gamester (2018) discusses this sort of strategy at length and argues that it fails even if the substitution is granted.

13. As mentioned in note $7,\ulcorner$ “ $A$ " is true $\urcorner$ may have some additional content, but, if anything, that fact already poses problems for the disquotationalist's favored reading of (5) and (7). But I'm setting that issue aside here.

14. I do not wish to argue about labels here. If anyone does, then what I am arguing in this section is that the sort of view I am describing is particularly important, and it seems obvious that it is reasonably called 'disquotationalism'. Why that view that is my focus here is part of what I am in the process of explaining.

15. Modulo, as David (2005, p. 387) points out, following Moore (1953, p. 276), the commitment to the existence of the proposition that $A$. Compare note 7 , again. I'll now stop pointing out this kind of caveat. Consider it included throughout in what follows.

16. I hope it is clear that whether the verbal string "Snow is white is true" (or the written one, with or without extra quotation marks) can be understood, in colloquial English, as equivalent to "That snow is white is true" is wholly irrelevant. We are not doing ordinary language philosophy here but are discussing the status of "true" as a predicate specifically of sentences.

17. I will focus here on truth-theoretic semantics, but it should be clear, I hope, that nothing depends upon this restriction. The disquotationalist's task would only be harder if we were discussing a semantic theory that made use of more complex sorts of semantic values.

18. Of course, if such generalizations as (10) are supposed to 'express' claims that do not really involve truth, then attributions of truth to single sentences must do so as well: I.e., $\ulcorner$ “ $A$ ” is true $\urcorner$ must really 'express' a claim that does not involve truth. The only candidate is what is expressed by $A$ itself. Hence, again, the redundancy of disquotational truth.

19. I have made this point before (Heck, 2004, pp. 331-332), but in a somewhat different context, and without sufficient emphasis. Halbach (2001, p. 192, fn. 26) seems to agree with it.

20. One might think that (13) should express an infinite conjunction of infinite conjunctions, but this does not evade the problem, since the terms of that conjunction are the same as in the cases we shall discuss, and the difference is only one of grouping.

21. A missing bracket in "Truth and Disquotation" may have obscured what formula (12) on p. 332 was meant to be. It was what is (15) here.

22. The notion of a tautology is definable in PA, so we can interpret a theory containing that principle in one with, say, just the $\mathrm{T}$-sentences by reinterpreting $\mathrm{T}(x)$ to mean: $\mathrm{T}(x)$, in the old sense, or $x$ is a tautology.

23. J. L. Austin (1950, p. 122) famously regarded "true" as an "extraordinary word". But it has never been clear to me on what ground. Words are words.

24. I owe this point to Jamie Tappenden, who remarked in 1995 or so that, even if the extension of the truth-predicate is fixed by something like convention (T), it does not follow that we cannot go on to theorize about the set of true sentences and formulate possibly significant generalizations about it. McGee (2005, p. 144) has since made essentially the same point.

25. Horwich's discussion proceeds in terms of propositional truth, and so his position in Truth is not obviously disquotationalist. But Horwich is, in fact, committed to disquotationalism, since he is also committed to a deflationist view of meaning (Horwich, 1998). 
26. Formally speaking, if we take a theory $\mathcal{T}$ and add to it all $\mathrm{T}$-sentences for sentences in the language of $\mathcal{T}$, then the resulting theory is locally interpretable in $\mathcal{T}$ (Heck, 2018a, Theorem 2.1).

27. Here's an example. Let $\mathcal{T}$ be a theory. Suppose we have a theory of truth for $\mathcal{T}$ that allows us to prove the T-sentences. Then, if $\mathcal{T}$ is finitely axiomatized, we will also be able to prove, pretty trivially, that all of $\mathcal{T}$ 's axioms are true. But what if $\mathcal{T}$ is not finitely axiomatized or not even finitely axiomatizable? In that case, we cannot, in general, prove that all of $\mathcal{T}$ 's axioms are true, though we can prove that each of them is. To prove the stronger claim, we typically need to appeal to compositional principles (Heck, 2015, §3.4).

28. This sort of argument is outlined by Field (1994, pp. 258-259), who actually discusses the case of disjunction. I'll discuss conjunction, for reasons that will become clear below. There are similar arguments to be found in the writings of many others. I learned of such arguments as a student from Sir Michael Dummett, who discusses something similar in The Logical Basis of Metaphysics (Dummett, 1991, pp. 56ff).

29. This sort of suggestion was made during the discussion period when I presented related material at Princeton in 2009. Cieśliński (2010, p. 412) comes close to making it in print in his discussion of the conservativeness argument against deflationism. He seems simply to assume, however, that the deflationist is entitled to the compositional principles when he adopts what he calls $\mathrm{PA}(S)^{-}$as his base theory. That entitlement is precisely what I am questioning here.

30. Actually, it is not entirely clear that generalizations 'like' (9) would suffice, anyway. See, for example, the wide variety of truth-involving principles discussed by Friedman and Sheard (1987, 1988).

31. It isn't always clear whether disquotationalism is supposed to be a 'revolutionary' or 'hermeneutic' view. The point to be made next makes that moot in the present context. Still, my sense is that many disquotationalists have overlooked the importance of the issues I am discussing here because they have tended to focus on formal languages.

32. It is of course open to a disquotationalist to reply that semantics should be done in other terms, e.g., in terms of inference-rules. But surely it is an empirical question how semantics should be done. It would be odd if disquotationalism, a view defended entirely on a priori grounds, had such empirical implications.

33. The usual language of PA includes only function symbols for succession, addition, and multiplication, and exponentiation is then defined as a relation which can be proven (in PA, or in $I \Sigma_{1}$, but not in $I_{0}$ ) to satisfy existence and uniqueness conditions.

34. Feferman introduces the notion as a 'more natural' way of developing ideas which with he was, in one form or another, concerned throughout his career (Feferman, 1962, 1991).

35. Just to be clear: I have no interest in conceptual role semantics myself.

36. Gupta $(1993, \S 5)$ expresses some doubt about whether disquotationalists can understand the T-scheme as any kind of generalization. I think this is at best a stand-off and so shall not pursue the issue.

37. There's another interesting question in this same vicinity, namely, whether schematic reasoning might help explain what justification we have for regarding all the axioms of PA as true. There is no problem about why we regard each of the axioms as true: We accept the axiom, we accept the Tsentence for it, and we make a simple inference. But it is much less obvious with what right we regard all the axioms as true. In the context of an axiomatic 
theory of truth for the language of arithmetic, the proof is by induction, and the instance of induction we need necessarily involves semantic vocabulary. One might wonder if there is a different story to be told, however, along the lines we are discussing.

38. Long after this paper was completed, Leon Horsten and Graham Leigh (2017) showed that the compositional principles can be derived from socalled reflection principles. Unfortunately, I cannot consider their paper in any detail here. But many of the points to be made below apply mutatis mutandis. From the present point of view, what they observe is simply that reflection principles allow one to move from the observation that all instances of a scheme are provable to an assertion of that very scheme. (So their reflection principles are, in essence, an $\omega$-rule for sentences, as the editors remarked to me.) The arguments below largely concern restrictions on and presuppositions of that sort of move.

39. This is a fairly common idea in deflationist writing (see e.g. Hill, 2002), so it is no surprise that it should surface here.

40. As Schnieder (2011, pp. 445-446) notes, if 'cognitive equivalence' means that "a speaker who understands [two sentences] normally has to adopt the same epistemic stance towards them", then it may not support substitution within the scope of "because". One might think, in particular, that "It is true that snow is white because snow is white" is true, but the converse false, even though "Snow is white" and "It is true that show is white" are cognitively equivalent. But we have already seen that disquotational truth-predicates behave in sometimes surprising ways. We are simply seeing that again. (Special thanks here to Johannes Stern.)

41. Much the same point can be made about Horwich's attempt to deflate compositionality for meaning (Heck, 2013).

42. I am independently puzzled by this remark:

[I]n order for $[(22)]$ to be usable in a full compositional semantics, we'd also need other applications of substitutivity that are likewise dubious; e.g., we'd need that $S$ believes that ' $p$ or $q$ ' is true if and only if $S$ believes that ' $p$ ' is true or $S$ believes that ' $q$ ' is true (Field, 2005, p. 24).

I'm not sure what Field is thinking here-he doesn't explain further-and I cannot think of any reason myself that one would need such a principle in a compositional semantics, whether it was based upon (22) or not. In any event, the issue is whether Field is committed to (22), not what work (if any) it might do. (Possibly, what Field meant to write was: ... we'd need that $S$ believes that ' $p$ or $q$ ' is true if and only if $S$ believes that ' $p$ ' is true or ' $q$ ' is true. But that is unproblematic.)

43. As I mentioned in note 7 , these are not entirely equivalent: The former commits one to the existence of the sentence $A$. But it is not obvious that this commitment has to be the believer's, as opposed to the attributor's. To assume it did would be to make strong assumptions about how the content of the complement clause has to be related to the content of the belief attributed.

44. There is someone Superman knows can fly that Lois does not, because Superman knows that Clark Kent can fly, and Lois does not. But there may well not be anyone that Lois knows can fly that Jimmy does not, even though Lois knows that Superman can fly, and Jimmy does not know that Clark can fly. 
45. The issue remains controversial. Relevance theorists, in particular, often deny that "and" is truth-functional (see e.g. Carston, 1988).

46. More radically, one might deny that truth-functionality is an important phenomenon at all. But, again, my claim, at present, is just that disquotationalism cannot make sense of compositional principles as friends of semantics understand them. So we are faced with a choice between semantic theory and disquotationalism.

47. As is often noted, this sort of inference is valid in many logics in which the connectives are not truth-functional. For example, such inferences are valid in intuitionistic logic, in supervaluational systems, and so forth, and not just for conjunction but for the other connectives, as well, even though those connectives are not truth-functional in such systems.

48. Even an inference with premises $B$ and $C$ runs into similar problems, since "They had a baby. They got married." can seem relevantly similar to (23).

49. Note that the same point disposes of the suggestion that a connective * is truth functional just in case whether $A * B$ is completely determined by whether $A$ and whether $B$. Even if whether they got married and whether they had a baby does not completely determine whether they had a baby and they got married, it could yet be that "and" is truth-functional.

50. This is true even in simple cases like "He saw John in the mirror". The usual claim is that "He" cannot be bound by "John". But that claim makes little sense absent the background assumption that facts about binding imply facts about meaning, in this case, that such binding implies de jure coreference. As is often pointed out, "He" can perfectly well be de facto co-referential with "John".

51. Whereas it can mean, I think, that every class is such that most professors know some student who hates it. (This reading is more natural if "every" is stressed.) Even the question why that reading is less natural wants answering, and the explanation also adverts to structure.

52. Variable-free semantic theories would explain the phenomenon differently (see e.g. Jacobsen, 2014). But the remarks to follow also apply to them. Perhaps even more so, since syntax does so little work in such frameworks.

53. Modulo concerns about the paradoxes, of course, though those will affect this entire discussion and so may be set aside for the moment.

54. Indeed, (9) could be true even if (26) was not true: "Alex swims and Tony runs" might be an idiom.

55. There is a program in the foundations of mathematics known as 'reverse mathematics' (Simpson, 2009). It is sometimes said to involve deriving axioms from theorems.

56. See, for example, Field's deflationary treatment of quantification (Field, $2005, \S 5)$.

57. For defense of the interpretive claims made here, and some caveats, see Heck and May $(2018,2020)$.

58. Ernst Schröder (1972, p. 224) expresses this sort of view in his review of Frege's Begriffsschrift (1967). Hugh MacColl (1877, pp. 9-10) comes closest to the modern conception, but his official view is that the sentenceletters denote 'statements'.

59. These are the calculations that would now be done with truth-tables. Boole does not have those, however. His calculations are, instead, manipulations of algebraic formulae.

60. This point is argued in detail by Dummett in the early chapters of The Logical Basis of Metaphysics. He expresses it by saying that a "meaningtheory must ... incorporate a semantic theory” (Dummett, 1991, p. 63). 
61. The history of quantification theory can be used to illustrate these sorts of points, as well. But, for reasons of space, I'll have to defer that discussion to another time.

62. Indeed, the precise formulation of the principle of compositionality is controversial, and it is easy to find non-compositional treatments of various constructions in the literature (cf. Dever, 2006; Szabó, 2012). But these still make serious use of notions like reference and truth.

\section{References}

Austin, J. (1950). Truth. Proceedings of the Aristotelian Society, 24: 111-128.

Bar-On, D. and Simmons, K. (2007). The use of force against deflationism: Assertion and truth. In Greimann, D. and Siegwart, G., editors, Truth and Speech Acts: Studies in the Philosophy of Language, pages 61-89. Routledge.

Boole, G. (1847). The Mathematical Analysis of Logic, Being an Essay Towards a Calculus of Deductive Reasoning. Macmillan, Barclay, \& Macmillan.

Boole, G. (1854). An Investigation Into the Laws of Thought. Walton and Maberly.

Carston, R. (1988). Implicature, explicature, and truth-theoretic semantics. In R. M. Kempson, editor, Mental Representations: The Interface Between Language and Reality, pages 155-181. Cambridge University Press.

Cieśliński, C. (2010). Truth, conservativeness, and provability. Mind, 119: 409-422.

David, M. (2005). Some T-biconditionals. In AmourGarb, B. and Beall, J., editors, Deflationary Truth, pages 382-419. Chicago, Open Court.

Davidson, D. (1984). Truth and meaning. In Inquiries Into Truth and Interpretation, pages 17-36. Clarendon Press.

Davidson, D. (1990). The structure and content of truth. Journal of Philosophy, 87: 279-328.

Dever, J. (2006). Compositionality. In Lepore, E. and Smith, B. C., editors, The Oxford Handbook of Philosophy of Language. Oxford University Press.

Dummett, M. (1991). The Logical Basis of Metaphysics. Harvard University Press.

Feferman, S. (1962). Transfinite recursive progressions of axiomatic theories. Journal of Symbolic Logic, 27: 259-312.

Feferman, S. (1991). Reflecting on incompleteness. Journal of Symbolic Logic, 56: 1-49.

Feferman, S. (1996). Gödel's program for new axioms: Why, where, how and what? In P. Hájek, editor, Gödel' 96, volume 6 of Lecture Notes in Logic. Springer.

Field, H. (1994). Deflationist views of meaning and content. Mind, 103: 249285. Reprinted in Field, 2001, Ch. 4.

Field, H. (1999). Deflating the conservativeness requirement. Journal of Philosophy, 96: 533-540.

Field, H. (2001). Truth and the Absence of Fact. Clarendon Press.

Field, H. (2005). Compositional priniciples vs. schematic reasoning. The Monist, 89: 9-27.

Frege, G. (1967). Begriffsschrift: A formula language modeled upon that of arithmetic, for pure thought. Translated by S. Bauer-Mengelberg, in J. van 
Heijenoort, editor, From Frege to Gödel: A Sourcebook in Mathematical Logic 1879-1931, pages 5-82. Harvard University Press.

Frege, G. (1984a). Collected Papers on Mathematics, Logic, and Philosophy, McGuiness, B., editor. Basil Blackwell.

Frege, G. (1984b). Function and concept. Translated by P. Geach, in Frege 1984a, pages 137-156. Also in Frege 1997, pages 130-148.

Frege, G. (1984c). On sense and meaning. Translated by M. Black, in Frege 1984a, pages 157-177. Also in Frege 1997, pages 151-171.

Frege, G. (1997). The Frege Reader, Beaney, M., editor. Oxford, Blackwell.

Frege, G. (2013). The Basic Laws of Arithmetic. Translated by P. A. Ebert and M. Rossberg. Oxford University Press.

Friedman, H. and Sheard, M. (1987). An axiomatic approach to self-referential truth. Annals of Pure and Applied Logic, 33: 1-21.

Friedman, H. and Sheard, M. (1988). The disjunction and existence properties for axiomatic systems of truth. Annals of Pure and Applied Logic, 40: 1-10.

Gamester, W. (2018). Truth: Explanation, success, and coincidence. Philosophical Studies, 175: 1243-1265.

Gupta, A. (1993). A critique of deflationism. Philosophical Topics, 21: 57-81.

Halbach, V. (1999). Disquotationalism and infinite conjunction. Mind, 108: $1-22$.

Halbach, V. (2001). How innocent is deflationism? Synthese, 126: 167-194.

Heck, R. K. (2004). Truth and disquotation. Synthese, 142: 317-352. Originally published under the name "Richard G. Heck, Jr".

Heck, R. K. (2007). Meaning and truth-conditions. In Greimann, D. and Siegwart, G., editors, Truth and Speech Acts: Studies in the Philosophy of Language, pages 349-376. Routledge. Originally published under the name "Richard G. Heck, Jr".

Heck, R. K. (2010). Frege and semantics. In Potter, M. and Ricketts, T., editors, The Cambridge Companion to Frege, pages 342-378. Cambridge University Press. Originally published under the name "Richard G. Heck, Jr".

Heck, R. K. (2011). A logic for Frege's Theorem. In Frege's Theorem, pages 267-296. Oxford, Clarendon Press. Originally published under the name "Richard G. Heck, Jr".

Heck, R. K. (2012). Reading Frege's Grundgesetze. Clarendon Press. Originally published under the name "Richard G. Heck, Jr".

Heck, R. K. (2013). Is compositionality a trivial principle? Frontiers of Philosophy in China, 8: 140-155. Originally published under the name "Richard G. Heck, Jr".

Heck, R. K. (2015). Consistency and the theory of truth. Review of Symbolic Logic, 8: 424-466. Originally published under the name "Richard G. Heck, Jr".

Heck, R. K. (2018a). The logical strength of compositional principles. Notre Dame Journal of Formal Logic, 59: 1-33. Originally published under the name "Richard G. Heck, Jr".

Heck, R. K. (2018b). Logicism, ontology, and the epistemology of second-order logic. In Fred, I. and Leech, J., editors, Being Necessary: Themes of Ontology and Modality from the Work of Bob Hale, pages 140-169. Oxford University Press.

Heck, R. K. and May, R. (2018). Truth in Frege. In M. Glanzberg, editor, The Oxford Handbook of Truth, pages 193-215. Oxford University Press. 
Heck, R. K. and May, R. (2020). The birth of semantics. Journal for the History of Analytic Philosophy, 8, no 6: 1-31.

Hill, C. (2002). Thought and World: An Austere Portrayal of Truth, Reference, and Semantic Correspondence. Cambridge University Press.

Horsten, L. and Leigh, G. E. (2017). Truth is simple. Mind, 126: 195-232.

Horwich, P. (1990). Truth. Blackwell.

Horwich, P. (1998). Meaning. Clarendon Press.

Jacobsen, P. (2014). Compositonal Semantics: An Introduction to the Syntax/ Semantics Interface. Oxford University Press.

King, J. C. and Stanley, J. (2004). Semantics, pragmatics, and the role of semantic content. In Z. G. Szabó, editor, Semantics versus Pragmatics, pages 111-164. Oxford University Press.

Larson, R. and Segal, G. (1995). Knowledge of Meaning. MIT Press.

Linnebo, Ø. (2003). Frege's conception of logic: From Kant to Grundgesetze. Manuscrito, 16: 235-252.

MacColl, H. (1877). The calculus of equivalent statements and integration limits. Proceedings of the London Mathematical Society, IX: 9-20.

Marcus, R. B. (1972). Quantification and ontology. Nô̂s, 6: 240-250.

McGee, V. (1997). How we learn mathematical language. Philosophical Review, 106: $35-68$.

McGee, V. (2005). Afterword: Trying (with limited success) to demarcate the disquotational-correspondence distinction. In AmourGarb, B. and Beall, J., editors, Deflationary Truth, pages 143-152. Open Court.

Moore, G. E. (1953). Some Main Problems of Philosophy. Allen and Unwin.

Partee, B. (1984). Nominal and temporal anaphora. Linguistics and Philosophy, 7: 243-286.

Quine, W. V. O. (1956). Quantifiers and propositional attitudes. The Journal of Philosophy, 53: 177-187. Reprinted in Quine, 1976, Ch. 17.

Quine, W. V. O. (1970). Philosophy of Logic. Prentice Hall.

Quine, W. V. O. (1976). The Ways of Paradox and Other Essays. Harvard University Press.

Quine, W. V. O. (1986). Philosophy of Logic. Harvard University Press, 2nd edition.

Quine, W. V. O. (1987). Quiddities: An Intermittently Philosophical Dictionary. Belknap Press.

Quine, W. V. O. (1990). Pursuit of Truth. Harvard University Press.

Schnieder, B. (2011). A logic for "because". Review of Symbolic Logic, 4: 445465.

Schröder, E. (1972). Review of Frege's Conceptual Notation. Translated by T. W. Bynum, in T. W. Bynum, editor, Conceptual Notation and Related Articles, pages 218-232. Oxford University Press.

Shapiro, S. (1998). Proof and truth: Through thick and thin. Journal of Philosophy, 95: 493-521.

Simchen, O. (2012). Necessary Intentionality: A Study in the Metaphysics of Aboutness. Oxford University Press.

Simpson, S. (2009). Subsystems of Second Order Arithmetic. Cambridge University Press, 2nd edition.

Soames, S. (1988). Semantics and semantic competence. In Schiffer, S. and Steele, S., editors, Cognition and Representation, pages 185-207. Westview Press. 


\section{Richard Kimberly Heck}

Soames, S. (1999). Understanding Truth. Clarendon Press.

Strawson, P. F. (1950). Truth. Proceedings of the Aristotelian Society, 24: 129-156. Reprinted in Strawson, 1971, Ch. 10.

Strawson, P. F. (1952). Introduction to Logical Theory. Methuen.

Strawson, P. F. (1971). Logico-Linguistic Papers. Methuen.

Szabó, Z. G. (2012). The case for compositionality. In Hinzen, W., Machery, E. and Werning, M., editors, The Oxford Handbook of Compositionality, pages 64-80. Oxford University Press.

Tarski, A. (1944). The semantic conception of truth and the foundations of semantics. Philosophy and Phenomenological Research, 4: 341-375.

Textor, M. (2010). Frege on judging as acknowledging the truth. Mind, 119: 615-655.

Williams, M. (1999). Meaning and deflationary truth. Journal of Philosophy, 96: $545-564$. 